CLINICAL ALERT

\title{
Recommendations for the treatment and prevention of malaria: Update for the 2015 season in South Africa
}

\author{
L H Blumberg \\ Lucille Blumberg is an infectious diseases specialist and microbiologist, and Head of the Division of Public Health Surveillance and Response at the \\ National Institute for Communicable Disease, Johannesburg, South Africa. She has compiled this article for the South African Malaria Elimination \\ Committee (SAMEC), the national malaria advisory group to the National Department of Health, Pretoria, South Africa, in her capacity as \\ chairperson.
}

Corresponding author: Lucille Blumberg (lucilleb@nicd.ac.za)

Notified malaria cases in South Africa (SA) decreased significantly over the past 14 years, from over 60000 in the 1999/2000 malaria season to less than 13000 in 2013/2014. However, the past two seasons have seen increases in both local and imported cases. Mozambique contributes the highest number of imported cases in SA. This update provides recommendations for malaria treatment and prevention (in travellers and residents) for 2015 .

S Afr Med J 2015;105(3):175-178. DOI:10.7196/SAMJ.9407

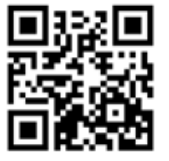

\section{Management of malaria}

Key components of successful management are early and accurate diagnosis (Table 1) and prompt treatment with effective drugs.

Treatment should ideally be based on confirmed parasitological diagnosis. ${ }^{[1,2]}$ Microscopy of Giemsa-stained thick and thin blood smears remains the diagnostic mainstay. ${ }^{[3]}$ Rapid antigen detection diagnostic tests (RDTs) are more widely accessible than expert microscopy, provide prompt results and are adequately sensitive for Plasmodium falciparum infections. However, RDTs cannot quantify parasite density (so do not detect hyperparasitaemia that indicates severe malaria) and are less sensitive for non-falciparum species than for falciparum infections. RDTs are unsuitable for monitoring treatment response because of antigen persistence. ${ }^{[4]} \mathrm{A}$ negative (rapid or microscopy) test does not exclude malaria; repeat testing within $8-24$ hours, without attempting to coincide with fever peak timing, is mandatory until a positive result or an alternative definitive diagnosis is achieved. Blood smears should be checked for malaria whenever thrombocytopenia is unexpectedly identified. Test any patient with unexplained fever for malaria, even in the absence of a travel history. Occasionally, infected mosquitoes are transported from endemic areas in suitcases and vehicles (Odyssean malaria). ${ }^{[5]}$ All malaria cases must be notified to local health authorities.

\section{Treatment of malaria}

The choice and route of treatment depends primarily on disease severity, which is often underestimated. Uncomplicated malaria is symptomatic infection without signs of severity or evidence of vital organ dysfunction. Persistent vomiting, clinical jaundice, change in mental state or increase in respiratory rate constitutes severe malaria (Table 2). ${ }^{[6,7]}$

Treat uncomplicated malaria with artemether-lumefantrine (Coartem) (Table 3). ${ }^{[2]}$ For optimal absorption it must be taken with milk or fat-containing food. Adequate fluids, temperature control with paracetamol, and careful follow-up are important. Avoid non-steroidal anti-inflammatory agents. Patients should respond clinically and parasitologically within $24-48$ hours. Consider poor compliance, misdiagnosis and possible drug resistance if no significant improvement occurs within 72 hours. Artemetherlumefantrine remains efficacious in South Africa (SA), ${ }^{[8,9]}$ with no reports of artemisinin resistance in Africa as yet. In the rare event of artemether-lumefantrine treatment failure despite full compliance, give a full directly observed 7-day course of oral quinine (plus doxycycline or clindamycin) in hospital.

Oral quinine, combined with 7 days of doxycycline, remains an alternative to artemether-lumefantrine (Table 4), but compliance is poor. In pregnancy or children aged $<8$ years, substitute clindamycin for doxycycline (Table 4). Doxycycline or clindamycin add no early

\section{Table 1. Diagnosis of malaria}

Keep a high index of suspicion for malaria in travellers to, or residents of, malaria transmission areas presenting with fever or other 'flu-like illness, irrespective of the time of year, intensity of transmission or use of chemoprophylaxis. Always take an adequate travel history.

Typical presentation: paroxysms of fever and rigors in adults, also headache, myalgia, loss of appetite, nausea and vomiting. In young children, fever, lethargy, poor feeding, vomiting and diarrhoea are most common.

Important differential diagnoses: meningitis, African tick-bite fever, typhoid, viral haemorrhagic fever, trypanosomiasis.

Progression to severe disease may be rapid, particularly in non-immune and immune-compromised persons, young children and pregnant women.

Often missed in patients with comorbid disease.

Frequently misdiagnosed in pregnancy, requiring differentiation from pregnancy complications including intrauterine and urinary tract infections. 
treatment benefit, so are started only once symptoms improve, as gastrointestinal side-effects may exacerbate those of quinine.

\section{Drug interactions}

Concomitant use of certain other drugs (e.g. efavirenz, rifampicin) may alter blood concentrations of artemether-lumefantrine and quinine. There is no evidence of the clinical significance of these interactions, but full adherence and fat co-administration is advised, and response to treatment should be monitored particularly carefully.

\section{Pregnancy}

First trimester. Supervised 7-day course of oral quinine plus clindamycin

\author{
Table 2. Clinical and laboratory criteria for severe malaria \\ (any one or combination of these criteria applies)

Clinical
Impaired consciousness, multiple convulsions
Respiratory distress, acidotic breathing, pulmonary oedema
Circulatory collapse
Jaundice
Bleeding
Prostration
Laboratory
Hypoglycaemia (blood glucose $<2.2 \mathrm{mmol} / \mathrm{L}$ )
Acidosis (plasma bicarbonate $<15 \mathrm{mmol} / \mathrm{L}$ or serum lactate
$>5$ mmol/L)
Hepatic transaminases $>3$ times normal
Renal impairment (serum creatinine $>265 \mu$ mol/L or rapidly
rising creatinine or urine output $<400 \mathrm{~mL} /$ day in an adult)
Haemoglobin $<5$ g/L
Parasitaemia $\geq 5 \%$
$\geq 5 \%$ neutrophils contain malaria pigment
Presence of schizonts of $P$ falciparum in peripheral blood smear

Second and third trimesters. Artemether-lumefantrine is considered safe and efficacious.

\section{Large adults}

Artemether-lumefantrine is registered in SA only for use in patients weighing $\leq 65 \mathrm{~kg}$. Minimal pharmacokinetic data exist for larger patients; one study suggests a trend towards increased risk of treatment failure in patients $>80 \mathrm{~kg}{ }^{[10]}$ Again, adequate adherence and fat co-administration is important, with careful monitoring of response. If adherence is assured, consider administering the same total dose over 5 days (dosing at $0,8,24,48,72$ and 96 hours).

\section{Recommendations for non-falciparum malaria}

Malaria species should be confirmed by a reliable laboratory. Nonfalciparum infections are usually uncomplicated, but occasionally produce severe illness. Use artemether-lumefantrine for initial therapy of uncomplicated $P$. vivax and $P$. ovale infections. To prevent relapses, this should be followed by a course of primaquine after excluding glucose-6-phosphate dehydrogenase (G6PD) deficiency.

Table 3. Dosing schedule for artemether-lumefantrine (Coartem)

\begin{tabular}{|c|c|c|c|c|c|c|}
\hline \multirow[b]{2}{*}{ Body weight (kg) } & \multicolumn{6}{|c|}{$\begin{array}{c}\text { Time of dosing (hours) and number } \\
\text { of tablets }\end{array}$} \\
\hline & $\mathbf{0}$ & $8-12$ & 24 & 36 & 48 & 60 \\
\hline $5-14$ & 1 & 1 & 1 & 1 & 1 & 1 \\
\hline $15-24$ & 2 & 2 & 2 & 2 & 2 & 2 \\
\hline $25-34$ & 3 & 3 & 3 & 3 & 3 & 3 \\
\hline$\geq 35$ & 4 & 4 & 4 & 4 & 4 & 4 \\
\hline
\end{tabular}

Table 4. Dosing schedule for oral quinine with doxycycline or clindamycin

\begin{tabular}{ll}
\hline Drug & Schedule \\
\hline Oral quinine & $10 \mathrm{mg} / \mathrm{kg}$ 8-hourly for 7 days \\
Doxycycline & $\begin{array}{l}200 \mathrm{mg} \text { stat, thereafter } 100-200 \mathrm{mg} \text { once daily, or } \\
3.5 \mathrm{mg} / \mathrm{kg} \text { once daily for } 7 \text { days }\end{array}$ \\
Clindamycin & $10 \mathrm{mg} / \mathrm{kg}$ bd for 7 days
\end{tabular}

Table 5. Dosing schedule and adverse effects for mefloquine, doxycycline and atovaquone-proguanil

\begin{tabular}{|c|c|c|}
\hline Chemoprophylactic & Schedule & Adverse effects \\
\hline Mefloquine (Lariam, Mefliam) & $\begin{array}{l}\text { Weekly, starting } 1-2 \text { weeks before travel, weekly } \\
\text { while there and continue for } 4 \text { weeks after } \\
\text { Adults: } 250 \mathrm{mg} \text { weekly } \\
\text { Children: } 5 \mathrm{mg} / \mathrm{kg} \text { weekly } \\
\text { Not recommended for children }<3 \text { months or } \\
<5 \mathrm{~kg}\end{array}$ & $\begin{array}{l}\text { Gastrointestinal, headache, dizziness, imbalance, } \\
\text { mood changes, insomnia, nightmares, and rarely, } \\
\text { psychosis. Increased risk of eye disorders } \\
\text { Contraindications: epilepsy, neuropsychiatric } \\
\text { disorders, those who require fine motor } \\
\text { co-ordination, divers and pilots }\end{array}$ \\
\hline Doxycycline (daily) & $\begin{array}{l}\text { Daily, starting } 1 \text { day before travel, daily while } \\
\text { there and continue for } 4 \text { weeks after } \\
\text { Adults: } 100 \mathrm{mg} \text { daily } \\
\text { Not recommended for children }<8 \text { years }\end{array}$ & $\begin{array}{l}\text { Skin photosensitivity, oesophagitis, upper } \\
\text { gastrointestinal symptoms, vaginal candidiasis or } \\
\text { diarrhoea (normal flora disruption) }\end{array}$ \\
\hline Atovaquone-proguanil (Malanil, Numal) & $\begin{array}{l}\text { Daily, starting } 1 \text { day before travel, daily while } \\
\text { there and continue for } 1 \text { week after } \\
\text { Adults: } 1 \text { tablet daily } \\
\text { Children > } 11 \text { kg: Malanil Paediatric at prescribed } \\
\text { dose per body weight }\end{array}$ & $\begin{array}{l}\text { Adverse reactions uncommon; include headache, } \\
\text { nausea, vomiting, abdominal pain, diarrhoea }\end{array}$ \\
\hline
\end{tabular}


Table 6. Drug choice according to patient factors

\begin{tabular}{|c|c|c|c|}
\hline Patient factor & Mefloquine & Doxycycline & Atovaquone-proguanil \\
\hline $\begin{array}{l}\text { Pregnancy - avoid travel to } \\
\text { malaria areas. }\end{array}$ & $\begin{array}{l}\text { Now recommended for all } \\
\text { trimesters }^{[12,13]} \text { if travel is } \\
\text { necessary. }\end{array}$ & Contraindicated & $\begin{array}{l}\text { Contraindicated owing to lack of } \\
\text { data. }\end{array}$ \\
\hline $\begin{array}{l}\text { Young children }- \text { avoid taking } \\
\text { children }<5 \text { years to high-risk } \\
\text { areas. }\end{array}$ & $\begin{array}{l}\text { Can be used in children } \\
>3 \text { months or }>5 \mathrm{~kg} \text {. Generally } \\
\text { well tolerated by children. }\end{array}$ & Use only in children $>8$ years. & $\begin{array}{l}\text { Paediatric tablets can be given to } \\
\text { children }>11 \mathrm{~kg} \text {. Breaking of tablets } \\
\text { is not recommended. }\end{array}$ \\
\hline $\begin{array}{l}\text { Persons requiring long-term } \\
\text { prophylaxis }\end{array}$ & $\begin{array}{l}\text { Can be used for up to } 3 \text { years. } \\
\text { Longer-term use may be } \\
\text { justified by risk of malaria. }\end{array}$ & $\begin{array}{l}\text { Can be safely used for up to } 2 \\
\text { years. Longer term use may be } \\
\text { justified by risk of malaria. }\end{array}$ & $\begin{array}{l}\text { Can be used confidently for up to } \\
1 \text { year. Longer-term use may be } \\
\text { justified by risk of malaria. }\end{array}$ \\
\hline HIV-positive (on ARVs) & & Best option & \\
\hline
\end{tabular}

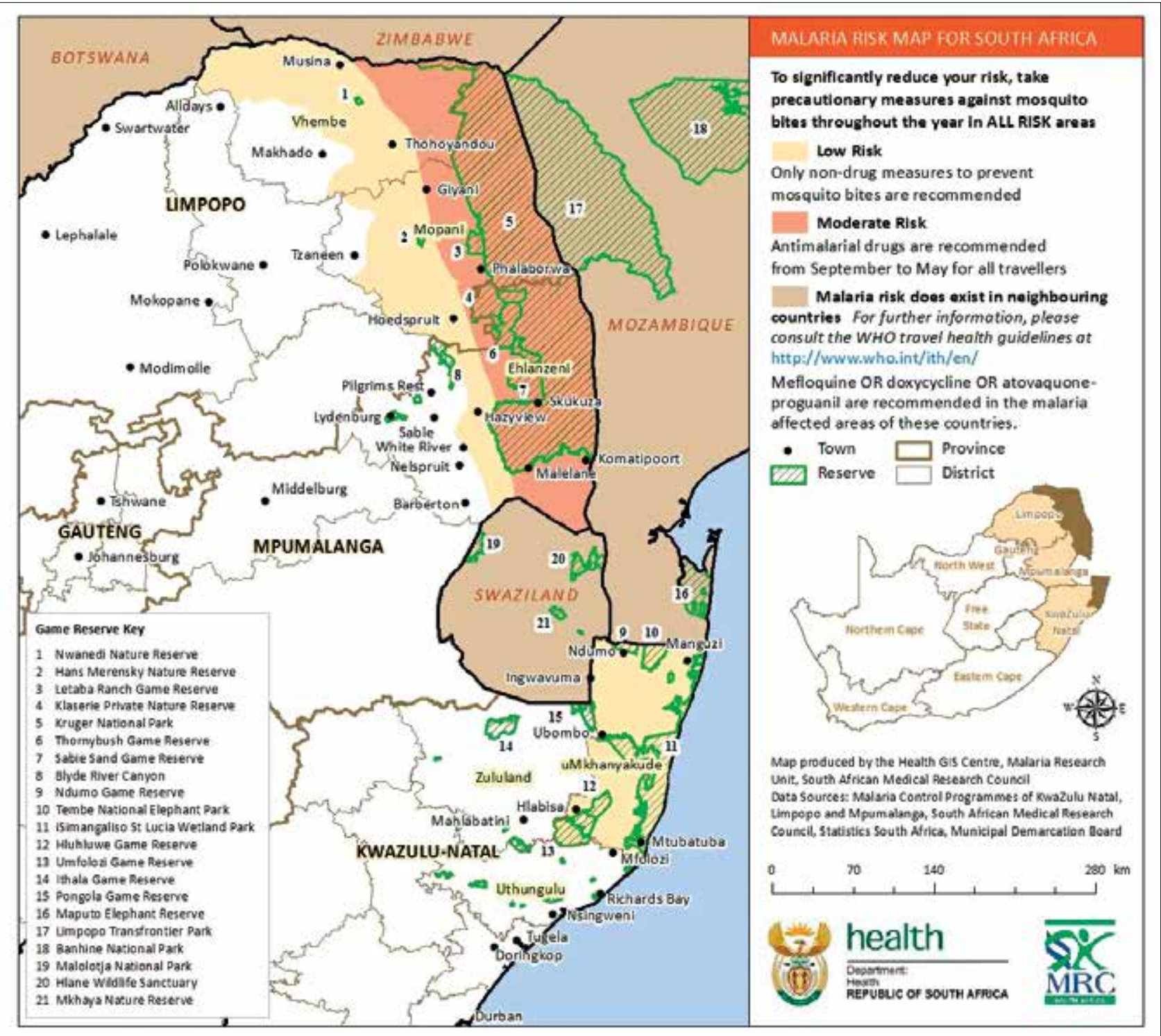

Fig. 1. Malaria risk map for SA (adopted 2014).

The recommended dose in children is $0.25-0.3 \mathrm{mg} / \mathrm{kg}$ daily for 14 days, and that for adults is $15 \mathrm{mg}$ daily for 14 days. Currently primaquine is only available on a named-patient basis with Section 21 MCC approval.

\section{Severe malaria (Table 5)}

Severe malaria is a medical emergency requiring prompt parenteral treatment, intensive nursing care, and careful monitoring and management of complications. ${ }^{[6.7]}$ Intravenous artesunate $(2.4 \mathrm{mg} / \mathrm{kg}$ 
at 0,12 and 24 hours, then daily until the patient is able to tolerate oral treatment) is preferred treatment, but is currently unregistered and only available on a named-patient basis with Section 21 MCC approval. ${ }^{[2,11]}$ When intravenous artesunate is not promptly available, intravenous quinine (with an initial loading dose of $20 \mathrm{mg} / \mathrm{kg}$ and then maintenance doses of $10 \mathrm{mg} / \mathrm{kg}$, each dose slowly infused over at least 4 hours) is initiated urgently and given 8 -hourly until oral treatment is tolerated. Follow with a complete course of artemetherlumefantrine. ${ }^{[2]}$ Reassess frequently to ensure that all complications are promptly detected and optimally managed.

\section{Critical issues in management of severe malaria}

Hypoglycaemia. Urgently exclude (or administer empiric glucose) if there is a depressed level of consciousness or convulsions. Repeat glucose monitoring 4-hourly.

Renal failure. This is a frequent, early complication in adults. Severe malaria requires careful fluid management, with frequent measurement of renal function (urea, electrolytes and creatinine), ongoing monitoring of urine output and judicious fluid administration. Strictly avoid overhydration, as the acute respiratory distress syndrome is a common and difficult-to-treat complication, particularly in pregnancy.

\section{Prevention of malaria}

Prevention of mosquito bites is the mainstay of malaria prevention. Malaria-transmitting mosquitoes generally bite at night, so people in malaria-endemic areas should ideally remain indoors from dusk to dawn, and sleep under insecticide-treated bednets in rooms with screened windows and doors. Fig. 1 shows endemic areas in $\mathrm{SA}$; residents and travellers in these areas should take necessary precautions to avoid mosquito bites.

Effective repellents contain DEET (diethyl toluamide). Use products containing 20 - 50\% DEET for long-lasting protection for adults and children aged $>2$ months. Products containing $>50 \%$ DEET have no additional benefit. Avoid applying to eyes or mouth.
Additionally, travellers to malaria-endemic areas should use chemoprophylaxis depending on the malaria risk assessment. Three similarly effective chemoprophylactic agents are currently registered in SA (Table 5), all requiring a doctor's prescription. Selection should be based on patient factors (Table 6) and which option is likely to be best tolerated for optimal adherence.

\section{Scope of protection}

Chemoprophylactics are most effective against parasite asexual blood stages. While they will prevent initial illness caused by all species, they will not prevent relapses due to $P$. vivax and $P$. ovale.

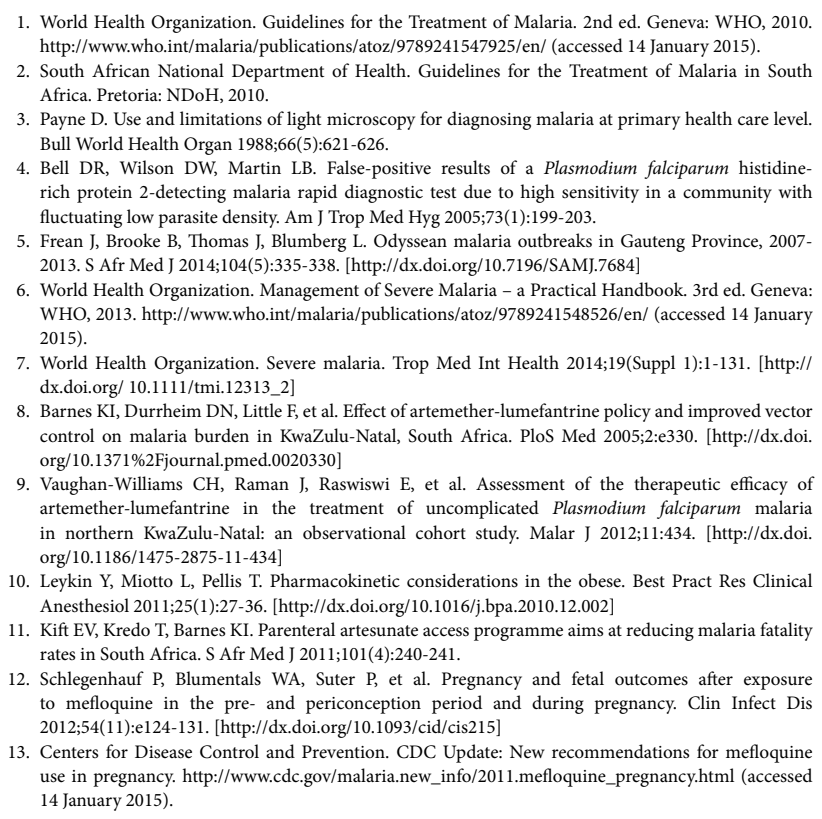
Accepted 26 January 2015

\section{This month in the $S A M J \ldots$}

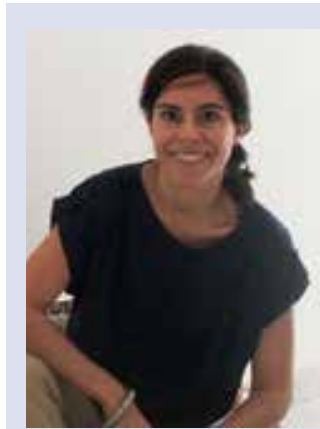

Maud Lemoine* is a clinical senior lecturer and honorary consultant in hepatology at St Mary's Hospital, Imperial College London. She completed her medical degree and a $\mathrm{PhD}$ in physiology and physiopathology in Paris, France, where she also graduated in political sciences from the Institute of Political Studies. She worked at the Medical Research Council laboratories in The Gambia, West Africa, running the PROLIFICA (Prevention of Liver Fibrosis and Cancer in Africa) project (EU-FP7) on hepatitis B virus and liver cancer. She is also leading a study on HIV/hepatitis C virus co-infection in Vietnam, funded by the ANRS (the French research agency on HIV/AIDS and viral hepatitis), and is co-investigator in a forthcoming pilot study on sofobuvir/ribavirinbased, interferon-free therapy in Cameroon, Côte d'Ivoire and Sénégal. She is a member of the World Health Organization scientific advisory board for the development of hepatitis $\mathrm{C}$ guidelines and of the ANRS.

*Howell J, Ladep NG, Lemoine M, et al. Prevention of Liver Fibrosis and Cancer in Africa: The PROLIFICA project - a collaborative study of hepatitis B-related liver disease in West Africa. S Afr Med J 2015;105(3):185-186. [http://dx.doi.org/10.7196/SAMJ.8880] 